\title{
Relationship between neuropathic pain and zinc ion
}

\section{Tomoya Kitayama*}

Department of Pharmacy, School of Pharmacy and Pharmaceutical Science, Mukogawa Women's University, Japan

Neuropathic pain characterized by spontaneous pain, pain sensation and tactile allodynia. The disease arising from peripheral or spinal nerve injury, diabetes, or infection with herpes virus is a result of the final product of an altered peripheral, spinal, and supraspinal process for which the usual analgesics are not effective and novel analgesics are desired.

The past study indicated that reduction of chloride gradient across the neuronal membrane, which in turn leads to reduction of anion reversal potential, occurred in neurons of the superficial dorsal horn following a peripheral nerve injury [1]. The mechanism of the change is down-regulation of $\mathrm{K}^{+}-\mathrm{Cl}^{-}$-cotransporter-2 (KCC2), which is potassium-chloride exporter, in spinal lamina I [1]. Similarly, the anion gradient is induced by brain-derived neurotrophic factor (BDNF) in neuropathic pain model animals [2]. BDNF induce decrease of KCC2 expression via activation of $\operatorname{TrkB}$ receptor. This alteration is one of likely mechanism which contributes to the production of allodynia and hyperalgesia associated with neuropathic pain. It is believed that microglia released BDNF. Many reports indicated relationship between microglia and BDNF signaling in neuropathic pain [3]. It was indicated that microglia played an important role in onset/development of neuropathic pain. However, the upstream signaling of BDNF-TrkBKCC2 cascade reaction is unclear. Although astrocytes are also considered to contribute to the initiation, rather to the maintenance of neuropathic pain, the role of astrocytes on development of neuropathic pain and underlying signaling cascades are not clear.

Recent reports suggested the relationship between zinc ion and neurodegenerative disease including spinal cord injury [4,5]. Zinc is an essential trace mineral that plays an important role such as growth and development, immune response, gene expression, wound healing, neurological function [6]. Zinc ion levels are strictly maintained by physiologic mechanisms. Transport of zinc ion requires specific zinc transporter proteins because zinc can't pass cellular membrane. In mouse, there are $14 \mathrm{Zip}$ transporters that increase intracellular zinc levels and $9 Z n T$ transporters that decrease intracellular zinc levels [6].

The alteration of zinc transporter proteins in zinc homeostasis induces to biochemical and physiological change. For example, lactational zinc deficiency suppresses TrkB signaling pathway and induces neuronal apoptosis [5]. High concentration of extracellular

Table 1. Relationship between neuropathic pain and zinc ion.

\begin{tabular}{|l|l|l|}
\hline Researcher & Year & Summary \\
\hline Ciubotariu et al. & 2015 & Zinc ion modulates opioid activity \\
\hline $\begin{array}{l}\text { Rodriguez- } \\
\text { Muňoz et al. }\end{array}$ & 2013 & Zinc ion modulates opioid receptor \\
\hline Lakhan et al. & 2012 & Zinc ion modulates pain via matrix metalloproteinases \\
\hline Jiang et al. & 2012 & Zinc ion inhibits acid-sensing ion channel \\
\hline Nozaki et al. & 2011 & Zinc ion modulates pain via NMDA receptor \\
\hline Jo et al. & 2008 & Depletion of vesicular zinc ion increases pain \\
\hline
\end{tabular}

zinc ion activates matrix metalloproteinases that convert pro-BDNF to mature-BDNF [7]. Zinc ion ionophore pyrithione inhibits KCC2 activity in vitro [8]. In other word, increase of zinc ion induces decrease KCC2 function. On the other hand, high synaptic zinc ion regulated by zinc transporter-3 elevates KCC2 activity via activation of metabotropic zinc ion sensing receptor [9]. These reports suggest that zinc ion concentration have an important relationship with $\mathrm{KCC} 2$ function. Moreover, it is considered that the alteration of zinc concentration modulates pain signaling.

We previously detected by microarray method that partial sciatic nerve ligation surgery induces the decreased expression of slc30a1 (zinc transporter 1, ZnT1) mRNA. The down regulation of ZnT1 gene was relationship with BDNF-TrkB-KCC2 cascade reaction in astrocyte [10]. The cascade reaction is that the down-regulated expression of ZnT1 increases intracellular zinc concentrations, enhances PKCa membrane translocation and NFKB nuclear translocation, up-regulates the expression of IL-6, increases the phosphorylation of CREB, and promotes the BDNF cascade reaction in astrocytes, all of which downregulate the expression of $\mathrm{KCC} 2$ and induce neuropathic pain in vivo [10].

The essential trace mineral include zinc is interesting. Recently, a lot of studies focus on zinc ion (Table 1). However, I think that it is possibility that the alteration of other essential trace mineral concentration is the upstream signaling of BDNF-TrkB-KCC2 cascade reaction and/or playing key role of development of neuropathic pain.

\section{References}

1. Coull JA, Boudreau D, Bachand K, Prescott SA, Nault F, et al. (2003) Trans-synaptic shift in anion gradient in spinal lamina I neurons as a mechanism of neuropathic pain. Nature 424: 938-942. [Crossref]

2. Coull JA, Beggs S, Boudreau D, Boivin D, Tsuda M, et al. (2005) BDNF from microglia causes the shift in neuronal anion gradient underlying neuropathic pain. Nature 438: 1017-1021. [Crossref]

3. Trang T, Beggs S, Salter MW (2011) Brain-derived neurotrophic factor from microglia: a molecular substrate for neuropathic pain. Neuron Glia Biol 7: 99-108. [Crossref]

4. Su R, Mei X, Wang Y, Zhang L (2012) Regulation of zinc transporter 1 expression in dorsal horn of spinal cord after acute spinal cord injury of rats by dietary zinc. Biol Trace Elem Res 149: 219-226. [Crossref]

5. Xu H, Gao HL, Zheng W, Xin N, Chi ZH, et al. (2011) Lactational zinc deficiencyinduced hippocampal neuronal apoptosis by a BDNF-independent TrkB signaling pathway. Hippocampus 21: 495-501. [Crossref]

Correspondence to: Tomoya Kitayama, Department of Pharmacy, School of Pharmacy and Pharmaceutical Science, Mukogawa Women's University, Japan, E-mail: tomokita@mukogawa-u.ac.jp

Received: November 12, 2016; Accepted: November 25, 2016; Published: November 28, 2016 
6. Fukada T, Kambe T (2011) Molecular and genetic features of zinc transporters in physiology and pathogenesis. Metallomics 3: 662-674. [Crossref]

7. Li C, Dabrowska J, Hazra R, Rainnie DG (2011) Synergistic activation of dopamine $\mathrm{D} 1$ and TrkB receptors mediate gain control of synaptic plasticity in the basolateral amygdala. PLoS One 6: e26065. [crossref]

8. Hershfinkel M, Kandler K, Knoch ME, Dagan-Rabin M, Aras MA, et al. (2009) Intracellular zinc inhibits KCC2 transporter activity. Nat Neurosci 12: 725-727. [Crossref]

9. Chorin E, Vinograd O, Fleidervish I, Gilad D, Herrmann S, et al. (2011) Upregulation of $\mathrm{KCC} 2$ activity by zinc-mediated neurotransmission via the $\mathrm{mZnR} / \mathrm{GPR} 39$ receptor. J Neurosci 31: 12916-12926. [Crossref]

10. Kitayama T, Morita K, Motoyama N, Dohi T (2016) Down-regulation of zinc transporter-1 in astrocytes induces neuropathic pain via the brain-derived neurotrophic factor - K+-Cl- co-transporter-2 signaling pathway in the mouse spinal cord. Neurochem 101: 120-131. [Crossref]

11. Ciubotariu D, Ghiciuc CM, Lupusoru CE (2015) Zinc involvement in opioid addiction and analgesia-should zinc supplementation be recommended for opioid-treated persons? Subst Abuse Treat Prev Policy 4: 29.

12. Rodriguez-Munoz M, Garzón J (2013) Nitric oxide and zinc-mediated protein assemblies involved in mu opioid receptor signaling. Mol Neurobilo 48: 769-782. [Crossref]

13. Lakhan SE, Avramut M (2012) Matrix metalloproteinases in neuropathic pain and migraine: friends, enemies, and therapeutic targets. Pain Res Treat 2012: 952906. [Crossref]

14. Jiang Q, Zha XM, Chu XP (2012) Inhibition of human acid-sensing ion channel $1 \mathrm{~b}$ by zinc. Int J Physiol Pathophysiol Pharmacol 4: 84-93. [Crossref]

15. Nozaki C, Vergnano AM, Filliol D, Ouagazzal AM, Le Goff A, et al. (2011) Zin alleviates pain through high-affinity binding to the NMDA receptor NR2A subunit. Nat Neurosci 14: 1017-1022. [Crossref]

16. Jo SM, Danscher G, Schroder HD, Suh SW (2008) Depletion of vesicular zinc in dorsal horn of spinal cord causes increased neuropathic pain in mice. Biometals 21: 151-158. [Crossref]

Copyright: (C2016 Dalisay A. This is an open-access article distributed under the terms of the Creative Commons Attribution License, which permits unrestricted use, distribution, and reproduction in any medium, provided the original author and source are credited. 